\title{
Fuzzy Plastic Constitutive Model and Its Application to Subgrade
}

\author{
Xigang Wang $\mathbb{D},{ }^{1}$ Liling Jin, ${ }^{1}$ Yang Xing, ${ }^{1}$ and Mingfu Fu ${ }^{2}$ \\ ${ }^{1}$ School of Resources and Civil Engineering, Liaoning Institute of Science and Technology, Xihu District, Benxi 117004, China \\ ${ }^{2}$ School of Civil Engineering and Architecture, Nanchang University, Honggutan District, Nanchang 330031, China
}

Correspondence should be addressed to Xigang Wang; fx_wxg@lnist.edu.cn

Received 16 July 2021; Revised 14 August 2021; Accepted 2 September 2021; Published 24 September 2021

Academic Editor: Angelo Aloisio

Copyright (C) 2021 Xigang Wang et al. This is an open access article distributed under the Creative Commons Attribution License, which permits unrestricted use, distribution, and reproduction in any medium, provided the original work is properly cited.

\begin{abstract}
The subgrade of a road is subjected to cyclic loading and unloading under the action of traffic loads. To study this mechanical response, the plastic membership function was introduced into the modified Cambridge model, and thus, the fuzzy plastic Cambridge constitutive model was obtained. With the continuous evolution of the plastic membership function from 0 to 1 , the fuzzy plastic Cambridge constitutive model continuously transitions the plastic properties inside and outside the initial yield surface. The evolution of the plastic membership function can replace the complex hardening law. The reliability of the model was verified using triaxial tests and simple cyclic loading and unloading tests. Using the finite element method, the mechanical response of the subgrade under cyclic loading was calculated. The fuzzy plastic Cambridge model can explain the insignificant yield characteristics of geotechnical media. In the fuzzy plasticity theory, the stress inside and outside the initial yield surface can produce plasticity. Absolute plasticity was not observed; only different degrees of plasticity existed.
\end{abstract}

\section{Introduction}

Numerous experiments have shown that most geotechnical media undergo plastic deformation at the beginning of loading, and geotechnical media do not have a clear yield point. The classical elastoplastic theory states that a geotechnical medium is elastic within the initial yield surface, which is worthy of discussion. The classical elastoplastic theory contradicts the uncertainty of the yield surface of geotechnical media. It is inappropriate to use the elastic theory to discuss problems pertaining to the initial yield surface of geotechnical media. The problems of cyclic loading and unloading of geotechnical media are also more complex. The calculation of cyclic loading and unloading requires multiple mathematical expressions. Owing to the existence of the initial yield surface, the finite element calculation is prone to discontinuities. In view of this, the calculation of plasticity, cyclic loading, and unloading of geotechnical media with respect to the initial yield surface is worth studying.

Two methods have been used to solve these problems. The first method uses the constitutive theory without a yield surface. In 1972, Bodner [1] proposed a unified elastic- viscoplastic model (basic dislocation mechanics). This model assumes no yield conditions, loading, or unloading. In 1971, Valanis [2] proposed an internal time theory without considering a yield surface. The endochronic theory posits that the neighborhood corresponding to the stress state at any point of plastic material is a function of deformation and temperature history. Irreversible changes in the internal structure of the material are expressed as internal variables, and the second method uses the elastoplastic constitutive theory with the yield surface. Sangrey et al. $[3,4]$ studied the dynamic characteristics of rock and soil under cyclic loading at low speeds and obtained the corresponding model. Fuijiwara [5, 6] used dynamic triaxial experiments to study the effects of the total load, load period, load increment ratio, loading method, degree of cementation, and number of cycles on deformation. The analysis revealed that the deformation caused by cyclic loading is greater than the corresponding static load deformation. Hu et al. [7] combined the triple-shear failure stress ratio with the modified Cambridge model for unsaturated soils; the triple-shear elastoplastic constitutive models for normally consolidated unsaturated soils under the single-stress variable and double-stress variable were built. Zhang et al. [8] studied the 
nonlinear creep of rocks. The proposed model can well reflect the effect of cyclic loading. The model is suitable for the accelerated creep stage of rock. Wu et al. [9] studied the process of energy accumulation in rocks. The method they proposed is suitable for loading and unloading analysis of rock spatial stability. Li et al. [10] studied the effect of temperature on the plastic damage of rocks. Ma et al. [11, 12] studied the influence of dry-wet cycles on the plastic mechanics of cement soil. In 1965, Zadeh introduced the concept of fuzzy mathematics in detail, which achieved good results [13]. In 1980, the fuzzy mathematics theory was introduced into structural reliability analysis by Yao. In 1988, fuzzy mathematics was applied to the theory of plastic mechanics by Klisinski [14]. Fu et al. established and demonstrated the uniqueness and existence of the fuzzy elastoviscoplastic constitutive model and its solution and studied the continuous transition of elastoplasticity in statics $[15,16]$. Wang et al. [17-19] studied the plastic membership function of geotechnical media. They obtained a fuzzy plastic constitutive model suitable for geotechnical media and presented a general method for transforming the plastic model into a fuzzy plastic model.

The yield of the soil is not obvious and the calculation of the cyclic loading and unloading process is complicated. In the theory of fuzzy mathematics, objects do not have absolute elasticity and plasticity, but only have varying degrees of plasticity. Different degrees of plasticity are represented by plastic membership functions. The plastic membership function can be used to quantitatively reflect the unobvious soil yield phenomenon. The continuous change of the plastic membership function can replace the complicated hardening law. The change of the plastic membership function can easily reflect the effect of cyclic loading and unloading. The continuous change of the plastic membership function can replace the complicated hardening law. A fuzzy plastic model is more suitable for cyclic loading and unloading problems.

\section{Methods}

2.1. Membership Function. The yield function $(f=0)$ is the criterion for judging whether the material is elastic or plastic. Let the area over the traditional yield surface be a fuzzy set $C$. This fuzzy set represents the elastic area of the yield surface. Let the elastic area constitute the domain of interest $\Sigma$.

Let $C$ be a fuzzy subset of the elastic region $\Sigma$ in the yield plane. Then, for any $\sigma \in \Sigma$, there is always a membership function $\mu(\sigma) \in[0,1]$, and its mapping relationship is

$$
\mu(\sigma): \sum \longrightarrow[0,1],
$$

where $\mu(\sigma)$ represents the degree of membership of the plastic behavior of the material in the stress state. This is a continuous function over the entire stress range. Any $\sigma$ in the fuzzy domain always has a membership function $\mu(\sigma) \in[0,1]$ associated with it. When $\sigma$ falls within the yield surface $(f<0), \mu(\sigma) \in(0,1)$, and the value of $\mu(\sigma)$ indicates the degree to which the stress point belongs to plasticity; when $\sigma$ falls on the yield surface or outside the yield surface $(f=0)$, then $\mu(\sigma)=1$, indicating that the stress point belongs to the plastic state up to $100 \%$; that is, the stress state enters the plastic region $[20,21]$.

If the yield limit of the traditional yield function is $k$, then the fuzzy yield limit function can be written as $k^{*}=k^{*}[k, \mu(\sigma)]$ and satisfies the following conditions:

$$
\begin{aligned}
& k^{*}[k, 0]=0, \\
& k^{*}[k, 1]=k .
\end{aligned}
$$

The yield function $f^{*}=f^{*}\left(\sigma, k^{*}\right)$ is called a fuzzy yield function. When $\mu(\sigma)=\lambda$, the corresponding fuzzy yield function is

$$
f_{\lambda}^{*}=f^{*}\left(\sigma, k^{*}[k, \lambda]\right) .
$$

For any $\lambda_{1}, \lambda_{2} \in[0,1]$, if $\lambda_{1}<\lambda_{2}$, the area formed by the fuzzy yield function $f^{*}{ }_{\lambda_{2}}=0$ contains the fuzzy yield function. The area formed by $f^{*}{ }_{\lambda_{1}}=0 . \lambda$ changes in the interval $[0,1]$. This change makes $f^{*}{ }_{\lambda}=0$ a variable surface, which reflects the degree of plastic membership corresponding to the stress state of the object. The change in the fuzzy yield surface of the object is shown in Figure 1.

In the elastoplastic theory, the problem of cyclic loading and unloading is more complicated. In order to make the cyclic loading and unloading path clearer, we build a fuzzy cone surface based on the concept of the fuzzy yield surface. The state of stress can be linked to the degree of plasticity of the object by blurring the standard plane. The continuous change of the degree of plasticity represents the continuous change of the fuzzy yield surface. The continuous change of the fuzzy yield surface indicates different loading and unloading states. In order to facilitate the explanation, the fuzzy cone adopts a linear form. In the follow-up study, we can use inversion analysis to determine a more appropriate form of the fuzzy reference surface.

Each stress point in the stress space in the classical yield surface corresponds to a plastic membership function value $\mu(\sigma)$ one-to-one, and the value of the plastic membership function depends on the magnitude of the stress invariant at this point. Figure 2 shows a fuzzy cone composed of membership and stress. It shows the relationship between the cyclic loading and unloading processes and the membership function. The stress path of the cyclic loading and unloading process was ABCOEDCOFB. This corresponds to the following sequence: first load along the $\mathrm{AB}$ path from zero, unload to zero along the fuzzy yield surface $\mathrm{BC}$, pass through the center of the fuzzy yield surface $\mathrm{CAO}$, load in the $\mathrm{OE}$ direction, change the load along the ED neutral, and then unload to zero along the fuzzy yield surface DC; subsequently, the path once again passes through CAO (zero stress) load in the positive direction along $\mathrm{OF}$, and then, the neutral variable load reaches B through FB. The evolution of the membership function can be expressed as a complete loading and unloading process, replacing the complex hardening law.

In fuzzy plasticity theory, the hardening process uses the fuzzy hardening modulus; that is, each fuzzy yield function corresponds to a fuzzy hardening modulus, which is a 


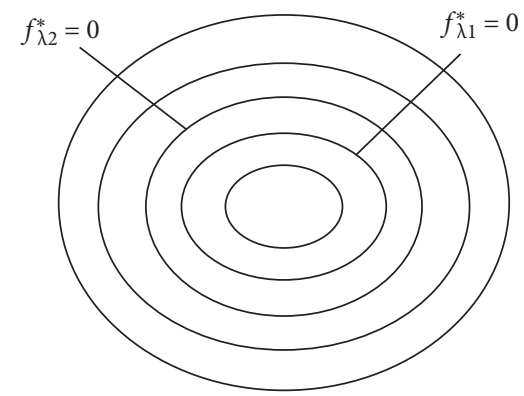

Figure 1: Fuzzy plastic yield surface.

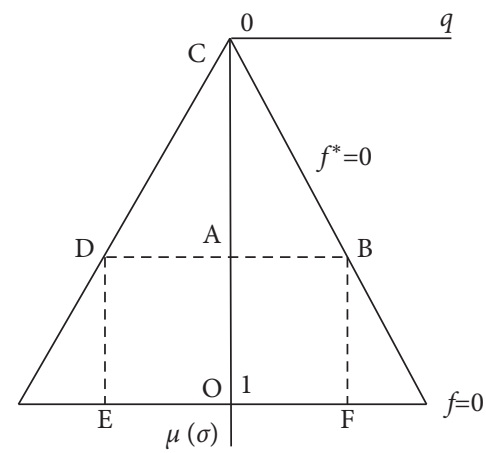

FIgURE 2: Evolution path of plastic membership function.

function of the classical plastic modulus and the degree of plastic membership $\mu(\sigma)$, expressed as follows:

$$
h^{*}=h^{*}(H, \mu(\sigma)),
$$

where $h^{*}$ is the fuzzy hardening modulus and $H$ is the classic hardening modulus.

Equation (4) should satisfy

$$
\begin{aligned}
& h^{*}=h^{*}(H, 0)=0, \\
& h^{*}=h^{*}(H, 1)=H .
\end{aligned}
$$

2.2. Modified Cambridge Model of Plastic Membership Function. The modified Cambridge model of the critical state is as follows:

$$
q=M * p .
$$

According to the energy equation and the associated flow law, the plastic potential function of the Cambridge model has the same form as that of the yield function:

$$
f=p^{2}-p * p_{\max }+\left(\frac{q}{M}\right)^{2}=0 .
$$

When $q=0$, it corresponds to the intersection point $p_{\max }$ of the classical initial yield surface and the $p$-axis. In Figure 1, the stress point in the elastic region does not satisfy equation (7). To ensure that the stress point in the elastic region meets the corresponding yield function, it is necessary to move the yield function and the $p$-axis intersection point $p_{\max }$ to the left to a certain intersection point $p_{\max }^{*}$. The result is that the original stress point in the elastic region is located on the corresponding fuzzy yield surface, as shown in Figure 3.

As the intersection point $p_{\max }^{*}$ moves from right to left, the stress point in the elastic region falls on the corresponding fuzzy yield function $f^{*}$, as shown in Figure 1. The plastic membership degree corresponding to the stress point on the classical initial yield surface is defined as 1, and the plastic membership degree of the stress point in the initial zero-load stress state is defined as 0 . The plastic membership function form is taken as

$$
\mu(\sigma)=\left(\frac{p_{\max }^{*}}{p_{\max }}\right)^{\alpha},
$$

where $\alpha$ is the parameter of the plastic membership function, which can be determined using the triaxial test data. The value range of $p_{\max }^{*}\left[0, p_{\max }\right]$ corresponds to the value range of the plastic membership function $[0,1]$. When $p_{\max }^{*}=0$, it means that the stress state of the material is loaded, that is, $\mu(\sigma)=0$; when $p_{\max }^{*}=p_{\max }$, the stress state of the material is on the classical initial yield surface, $\mu(\sigma)=1$. $p_{\max }^{*}$ determines the value of the plastic membership function, and $p_{\max }^{*}$ corresponds to the fuzzy plastic yield function and a soil plastic material membership function calculation result.

The plastic membership function parameter $\alpha$ influences the evolution of the membership function depending on the effect of different plasticity evolutions of the membership function, as shown in Figure 4.

As shown in Figure 4, with an increase in $p_{\max }^{*}$, the plastic membership function continuously increases from 0 to $100 \%$, and the degree of plastic strain increases; under the same stress (load), the smaller the degree of plasticity corresponding to $\alpha$, the larger the value of $\alpha$, and the smaller the plastic strain. For different soil materials, the value of $\alpha$ can be determined experimentally.

The fuzzy yield function can be obtained as follows:

$$
f^{*}=p^{2}-p * p_{\max }^{*}+\left(\frac{q}{M}\right)^{2}=0 .
$$

2.3. Fuzzy Plastic Constitutive Model. The fuzzy plastic Cambridge model adopted the associated flow law; its plastic hardening parameter was the plastic body strain $\varepsilon_{v}^{p}$, the plastic strain increment was orthogonal to the plastic potential surface, and the isotropic consolidation test was used. The test results are shown in Figure 5, where the initial void ratio of the soil sample is $e_{0}$, and the slopes of the loading and unloading curves are $\lambda$ and $\kappa$, respectively.

In Figure 3, when any point in the elastic region is loaded from $p_{0}$ to $p_{\max }^{*}$, the change in the void ratio is

$$
\Delta e=e-e_{0}=-\lambda \ln \frac{p_{\max }^{*}}{p_{0}} .
$$

The total volumetric strain can be expressed as

$$
\varepsilon_{v}=\frac{-\Delta e}{1+e_{0}}=\frac{\lambda}{1+e_{0}} \ln \frac{p_{\max }^{*}}{p_{0}} .
$$

According to equation (11), it can be seen that 


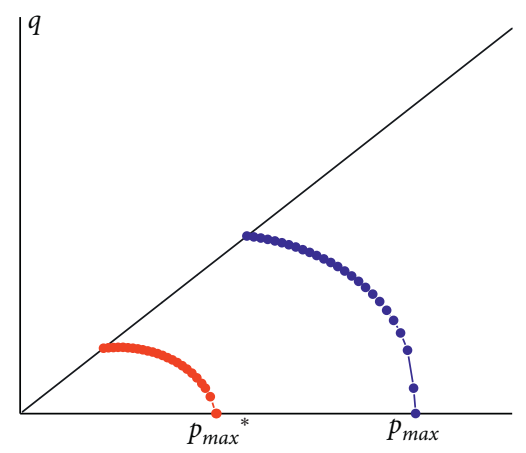

FIgURE 3: Fuzzy yield surface.

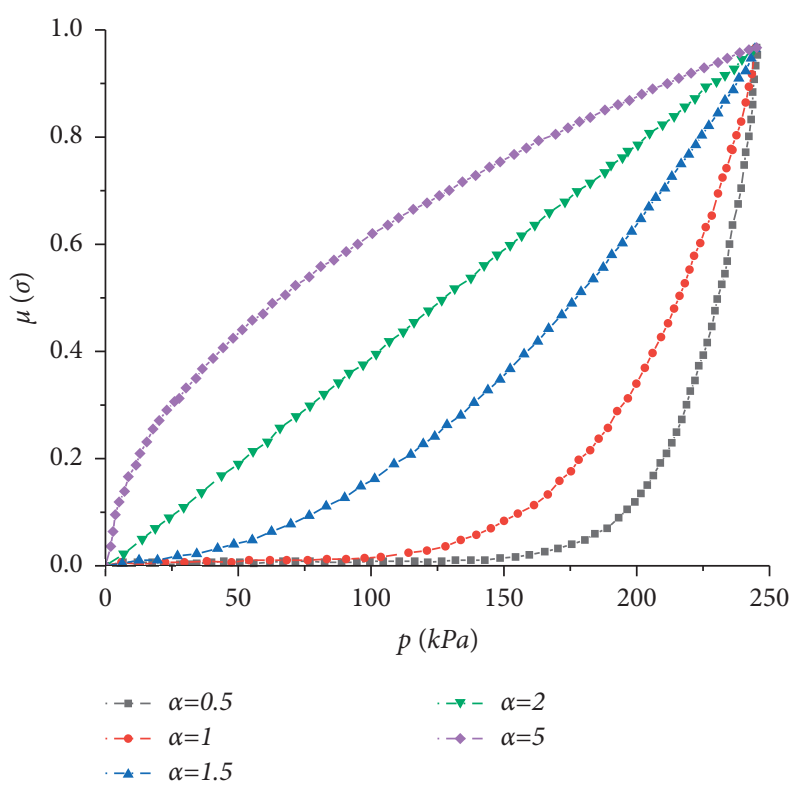

FIgURe 4: Evolution of plastic membership.

$$
\begin{aligned}
\varepsilon_{v}^{e} & =\frac{\kappa}{1+e_{0}}\left(\ln p_{\text {max }}^{*}-\operatorname{In} p_{0}\right), \\
\varepsilon_{v}^{p^{*}} & =\frac{\kappa}{1+e_{0}}\left(\ln p_{\max }^{*}-\ln p_{0}\right),
\end{aligned}
$$

where $\varepsilon_{v}^{p^{*}}$ is the fuzzy plastic volume strain corresponding to the fuzzy yield function $f^{*}, \varepsilon_{v}^{p^{*}}$ is the hardening parameter of the fuzzy plastic Cambridge model, and we obtain

$$
\ln p_{\max }^{*}=\frac{1+e_{0}}{\lambda-\kappa} \varepsilon_{v}^{p *}+\ln p_{0} .
$$

Through equation (14), we obtain

$$
p_{\max }^{*}=p_{0} * e^{1+e_{0} / \lambda-\kappa \varepsilon_{v}^{p *}} \text {. }
$$

Substituting equations (15) into (8), we obtain

$$
f^{*}=p^{2}-p * p_{0} * e^{1+e_{0} / \lambda-\kappa * \varepsilon_{v}^{P *}}+\left(\frac{q}{M}\right)^{2}=0 .
$$

Let $D_{p}=1+e_{0} / \lambda-\kappa$; then, the fuzzy yield function equation (16) becomes

$$
f^{*}=p^{2}-p * p_{0} * e^{D_{p} * \varepsilon_{v}^{p *}}+\left(\frac{q}{M}\right)^{2}=0
$$

According to the consistency conditions, we obtain

$$
\frac{\partial f^{*}}{\partial p} d p+\frac{\partial f^{*}}{\partial q} d q+\frac{\partial f^{*}}{\partial \varepsilon_{v}^{p *}} d \varepsilon_{v}^{p *}=0
$$

According to equation (9), we obtain

$$
\frac{\partial f^{*}}{\partial p}=2 p-p_{\max }^{*}=2 p-\sqrt[\alpha]{\mu} * p_{\max },
$$

$$
\frac{\partial f^{*}}{\partial q}=\frac{2 q}{M^{2}}
$$

$$
\frac{\partial f^{*}}{\partial \varepsilon_{v}^{p *}}=\frac{\partial f^{*}}{\partial p_{\max }^{*}} * \frac{\partial p_{\max }^{*}}{\partial \ln p_{\max }^{*}} * \frac{\partial \ln p_{\max }^{*}}{\partial \varepsilon_{v}^{p^{*}}} .
$$

According to equations (9) and (14) and with the differential operation, we obtain 


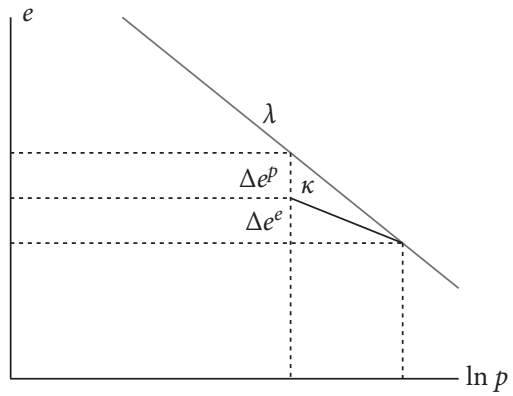

Figure 5: Changes in void ratio.

$\left\{\begin{array}{l}\frac{\partial f^{*}}{\partial p_{\max }^{*}}=-p, \\ \frac{\partial p_{\max }^{*}}{\partial \ln p_{\max }^{*}}=p_{\max }^{*}=\sqrt[\alpha]{\mu} * p_{\max } \\ \frac{\partial \ln p_{\max }^{*}}{\partial \varepsilon_{v}^{p *}}=\frac{1+e_{0}}{\lambda-\kappa}=D_{p} .\end{array}\right.$
Substituting equations (22) into (21), we obtain

$$
\frac{\partial f^{*}}{\partial \varepsilon_{v}^{p^{*}}}=-D_{p} * p * p_{\max }^{*}=-D_{p} * p * \sqrt[\alpha]{\mu} * p_{\max } .
$$

Using the associated flow rule, the plastic potential function is orthogonal to the plastic strain increment direction, which can be written as

$$
d \varepsilon_{v}{ }^{p *}=\Lambda^{*} * \frac{\partial g}{\partial p}=\Lambda^{*} * \frac{\partial f^{*}}{\partial q}
$$

where $\Lambda^{*}$ is the fuzzy plastic scale factor, indicating the plastic strain increment size, and $\partial g / \partial p$ indicates the plastic strain increment direction:

$$
\frac{\partial f^{*}}{\partial p} d p+\frac{\partial f^{*}}{\partial q} d q+\frac{\partial f^{*}}{\partial \varepsilon_{v}^{p *}} \Lambda^{*} \frac{\partial f^{*}}{\partial p}=0 .
$$

According to equations (22) and (25), the fuzzy plasticity variable factor $\Lambda^{*}$ is

$$
\Lambda^{*}=-\frac{\partial f^{*} / \partial p d p+\partial f^{*} / \partial q d q}{\partial f^{*} / \partial \varepsilon_{v}^{p *} * \partial f^{*} / \partial p}=\frac{\left(2 p-\sqrt[\alpha]{\mu} * p_{\max }\right) d p+2 q / M^{2} d q}{\left(2 p-\sqrt[\alpha]{\mu} * p_{\max }\right) * D_{p} * p * \sqrt[\alpha]{\mu} * p_{\max }}
$$

Substituting equations (26) into equation 24 , we obtain

$$
d \varepsilon_{v}^{p *}=\frac{\left(2 p-\sqrt[\alpha]{\mu} * p_{\max }\right) d p+2 q / M^{2} d q}{D_{p} * p * \sqrt[\alpha]{\mu} * p_{\max }} .
$$

The plastic work expression of the modified Cambridge model is as follows [22]:

$$
\begin{aligned}
d W^{P} & =p * d \varepsilon_{v}^{p *}+q * d \varepsilon_{d}^{p *} \\
& =p \sqrt{\left(d \varepsilon_{v}^{p *}\right)^{2}+\left(M d \varepsilon_{d}^{p *}\right)^{2}} .
\end{aligned}
$$

The final expression of equation (28) is

$$
\frac{d \varepsilon_{v}^{p^{*}}}{d \varepsilon_{d}^{p *}}=\frac{M^{2} * p^{2}-q^{2}}{2 p * q}
$$

According to equations (27) and (29), we obtain

$$
d \varepsilon_{d}^{p *}=\frac{2 q}{M^{2} * p^{2}-q^{2}} * \frac{\left(2 p-\sqrt[\alpha]{\mu} * p_{\max }\right) d p+2 q / M^{2} d q}{D_{p} * \sqrt[\alpha]{\mu} * p_{\max }} .
$$

The elastic strain increment is calculated according to the elastic theory, and the elastic strain increment of the modified Cambridge model after derivation is

$$
\left\{\begin{array}{l}
d \varepsilon_{v}^{e}=\frac{\kappa}{1+e_{0}} \frac{1}{p} d p, \\
d \varepsilon_{d}^{e}=\frac{2}{9} \frac{\kappa}{1+e_{0}} \frac{1+v}{1-2 v} \frac{1}{p} d q .
\end{array}\right.
$$

The total strain increment is composed of elastic strain increment and fuzzy plastic strain increment. According to equations (27), (29), and (31) it can be expressed as

$$
\left\{\begin{array}{l}
d \varepsilon_{v}=d \varepsilon_{v}^{e}+d \varepsilon_{v}^{p *}, \\
d \varepsilon_{d}=d \varepsilon_{d}^{e}+d \varepsilon_{d}^{p^{*}} .
\end{array}\right.
$$

\section{Analysis}

\subsection{Conventional Triaxial Tests}

3.1.1. Soil Parameters. We use an SDT-10-type microcomputer-controlled electrohydraulic servo dynamic geotechnical three-axis test system to conduct static and dynamic threeaxis experimental research on a soil sample. The sample was a reshaped cylindrical soil sample with a diameter of $39.1 \mathrm{~mm}$ and a height of $80 \mathrm{~mm}$; the sample was compacted in five layers using the layered wet pounding method to ensure the uniformity of the soil sample. In the triaxial pressure chamber, the soil sample was saturated by using airless water and applying backpressure, and the soil sample was consolidated until the soil sample's body deformation did not 
TABLe 1: Physical parameters of soil samples.

\begin{tabular}{lcccccc}
\hline$e$ & $\rho\left(\mathrm{g} / \mathrm{cm}^{3}\right)$ & $C(\mathrm{kPa})$ & $\varphi / 0$ & $\nu$ & $\lambda$ & \\
\hline 0.58 & 1.943 & 35 & 34 & 0.25 & 0.185 & 0.05
\end{tabular}

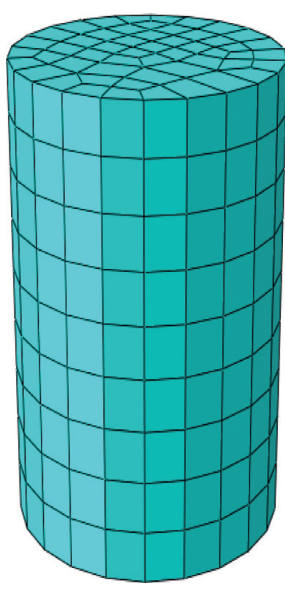

(a)

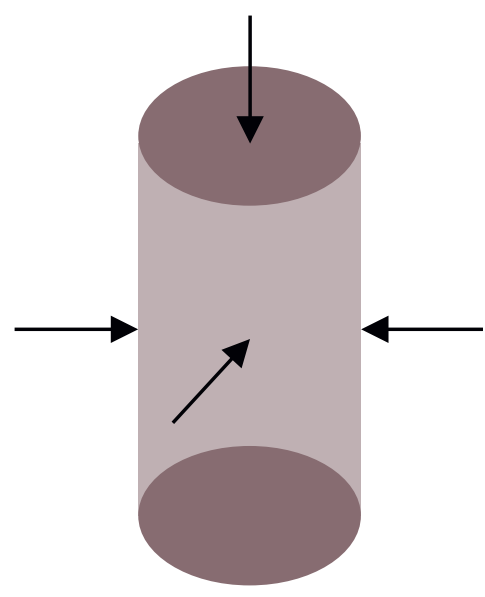

(b)

Figure 6: Soil sample finite element model. (a) Model grid. (b) Soil sample force diagram.

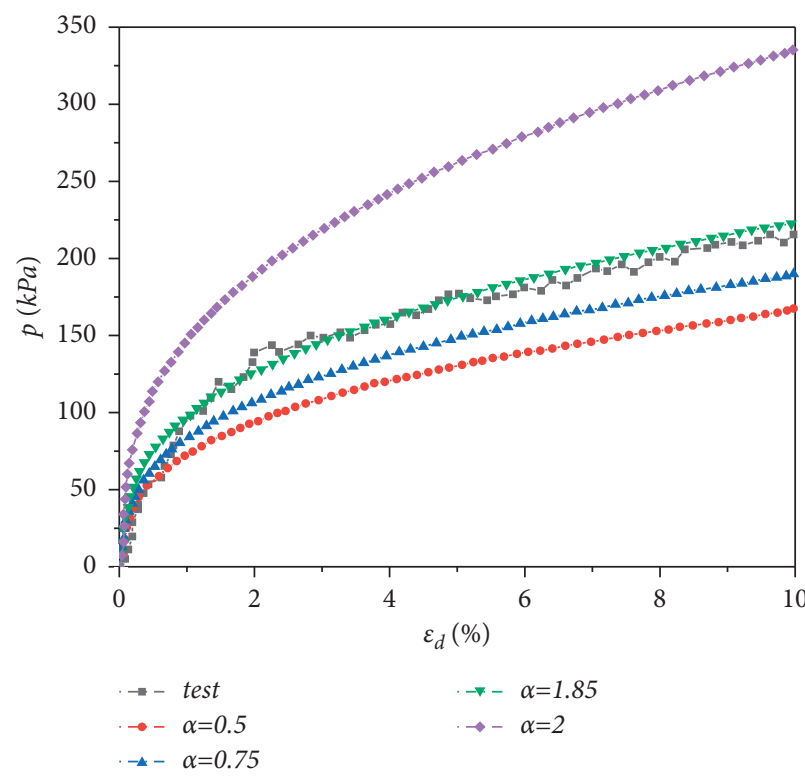

(a)

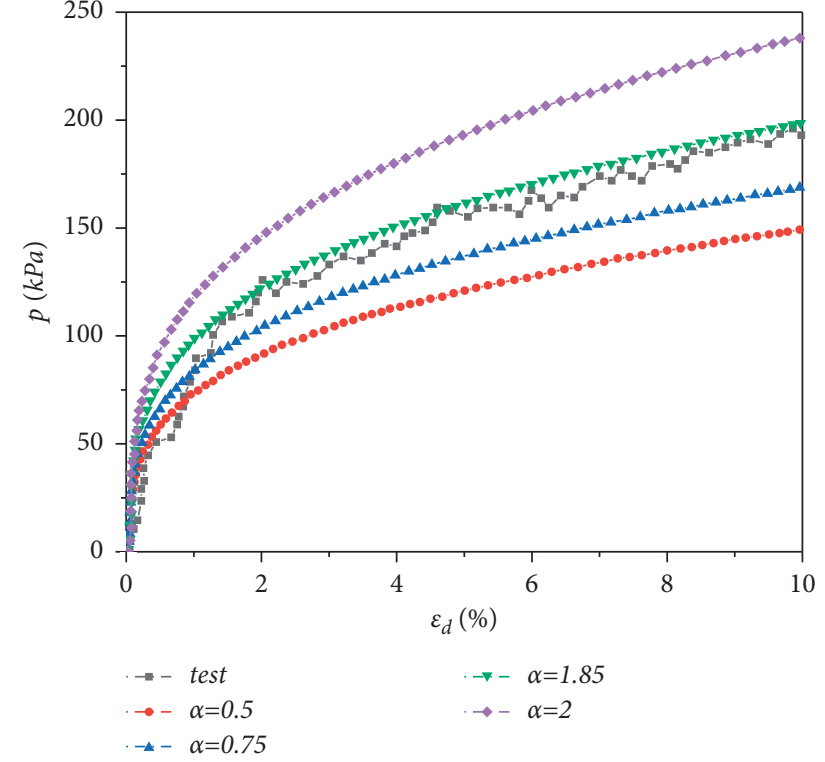

(b)

Figure 7: $q-\varepsilon_{d}$ curve. (a) $\sigma_{3}=100 \mathrm{kPa}$. (b) $\sigma_{3}=200 \mathrm{kPa}$.

change within $5 \mathrm{~min}$, after which point the sample was considered to be fully consolidated. The shear rate of the static triaxial test is $0.05 \%$. The basic physical parameters of the test soil samples are listed in Table 1.

Here, $e$ is the initial void ratio, $\rho$ is the density, $C$ is the cohesion, $\varphi$ is the friction angle, $\nu$ is Poisson's ratio, $\lambda$ is the total unloading slope, and $\kappa$ is the elastic unloading slope.

3.1.2. Triaxial Test Plan. Based on sufficient saturation, the sample was subjected to a conventional static triaxial experiment. The samples were subjected to static triaxial tests under confining pressures of 100 and $200 \mathrm{kPa}$. According to the fuzzy plastic theory, the finite element method was used to calculate the simulation results when the confining pressures were $100 \mathrm{kPa}$ and $200 \mathrm{kPa}$, and the finite element calculation results and the triaxial test results were compared and analyzed. A finite element model of the soil sample is shown in Figure 6.

3.1.3. Result Analysis. The drainage test results of the sample were obtained according to the triaxial experiment, and the calculation results of the sample were obtained according to 


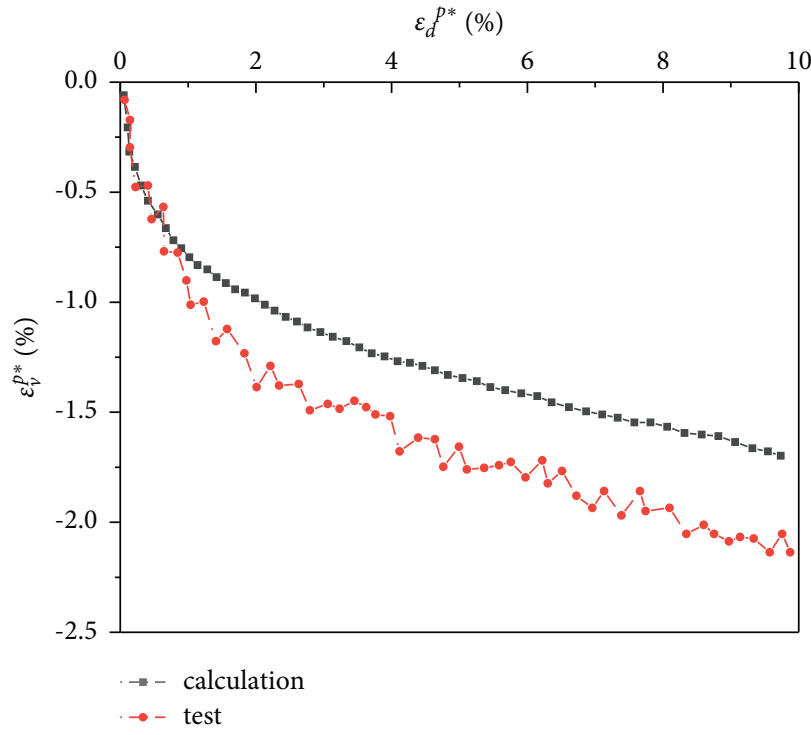

(a)

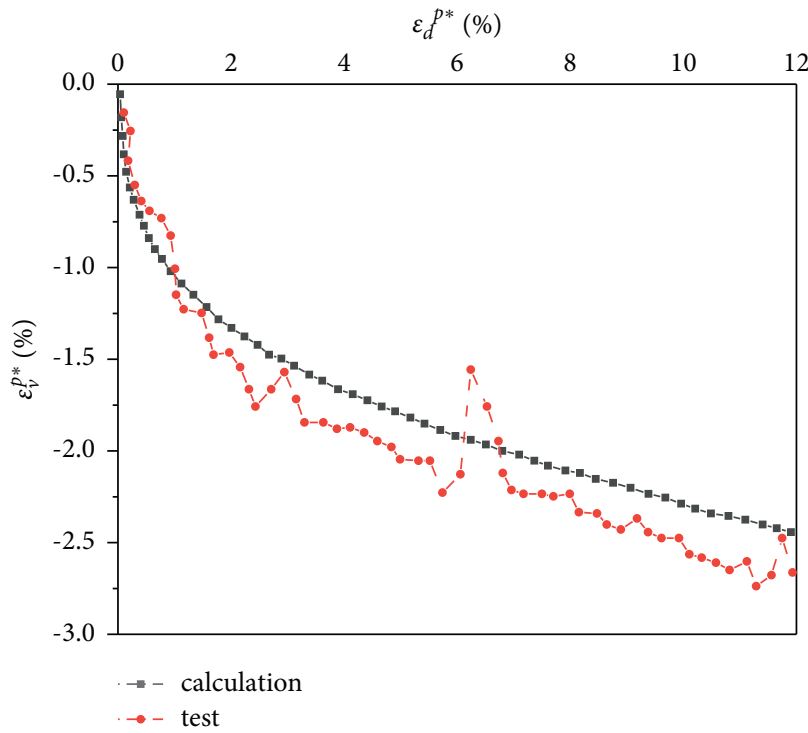

(b)

Figure 8: $\varepsilon_{v}-\varepsilon_{d}$ curve. (a) $\sigma_{3}=100 \mathrm{kPa}$. (b) $\sigma_{3}=200 \mathrm{kPa}$.

TABle 2: Correlation coefficient of model.

\begin{tabular}{lccc}
\hline$\sigma_{3}(\mathrm{kPa})$ & $\alpha$ & $R^{2}$ & Correlation \\
\hline 100 & 0.5 & 0.46 & Fair \\
100 & 0.75 & 0.65 & Fair \\
100 & 1.85 & 0.93 & Excellent \\
100 & 2 & 0.27 & Failed \\
\hline 200 & 0.5 & 0.43 & Fair \\
200 & 0.75 & 0.62 & Fair \\
200 & 1.85 & 0.91 & Excellent \\
200 & 2 & 0.23 & Failed \\
\hline
\end{tabular}

TABle 3: Experimental schemes for simple loading and unloading.

\begin{tabular}{|c|c|c|c|c|c|}
\hline$e_{0}$ & $\sigma_{3}(\mathrm{kPa})$ & $q_{j}(\mathrm{kPa})$ & $q_{d}(\mathrm{kPa})$ & $\eta$ & $f(\mathrm{~Hz})$ \\
\hline \multirow{4}{*}{0.786} & 100 & 50 & 10 & 0.1 & \multirow{4}{*}{1} \\
\hline & 100 & 50 & 20 & 0.2 & \\
\hline & 200 & 100 & 20 & 0.1 & \\
\hline & 200 & 100 & 30 & 0.2 & \\
\hline \multirow{4}{*}{0.853} & 100 & 50 & 10 & 0.1 & \multirow{4}{*}{1} \\
\hline & 100 & 50 & 20 & 0.2 & \\
\hline & 200 & 100 & 20 & 0.1 & \\
\hline & 200 & 100 & 30 & 0.2 & \\
\hline \multirow{4}{*}{0.923} & 100 & 50 & 10 & 0.1 & \multirow{4}{*}{1} \\
\hline & 100 & 50 & 20 & 0.2 & \\
\hline & 200 & 100 & 20 & 0.1 & \\
\hline & 200 & 100 & 30 & 0.2 & \\
\hline
\end{tabular}

the fuzzy Cambridge elastic-plastic constitutive model. The corresponding $q-\varepsilon_{d}$ and $\varepsilon_{v}-\varepsilon_{d}$ curves were obtained. The comparison results are shown in Figures 7 and 8 , where $q$ is the main stress difference, $\varepsilon_{d}$ is the axial strain, and $\varepsilon_{v}$ is the volume strain.
Figures 7(a) and 7(b) show that, under different confining pressures, when the membership function parameter $\alpha=1.85$, the experiment results are in good agreement with the $q-\varepsilon_{d}$ curve of the model results. It shows that the fuzzy elastoplastic Cambridge model can represent the 


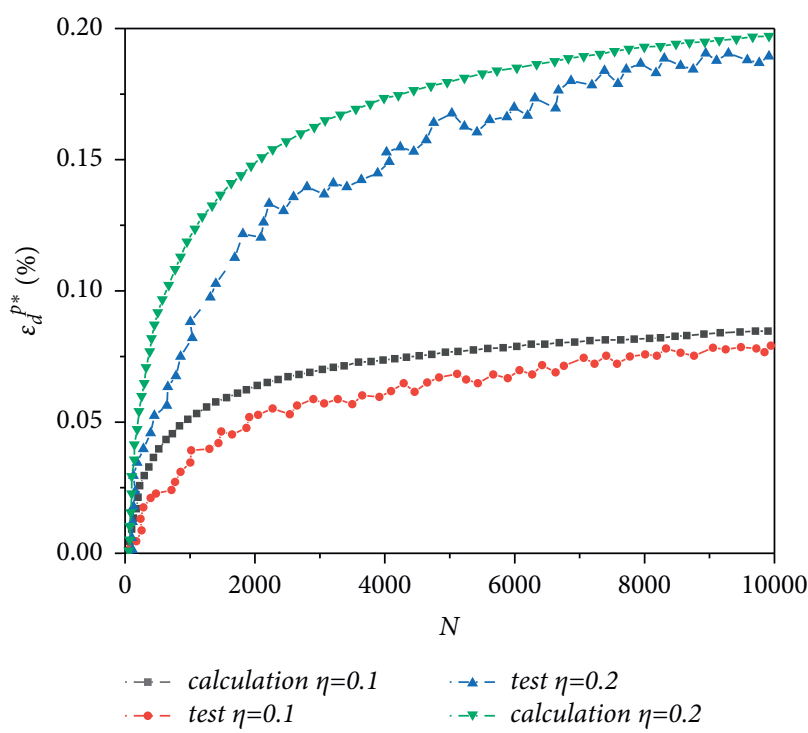

(a)

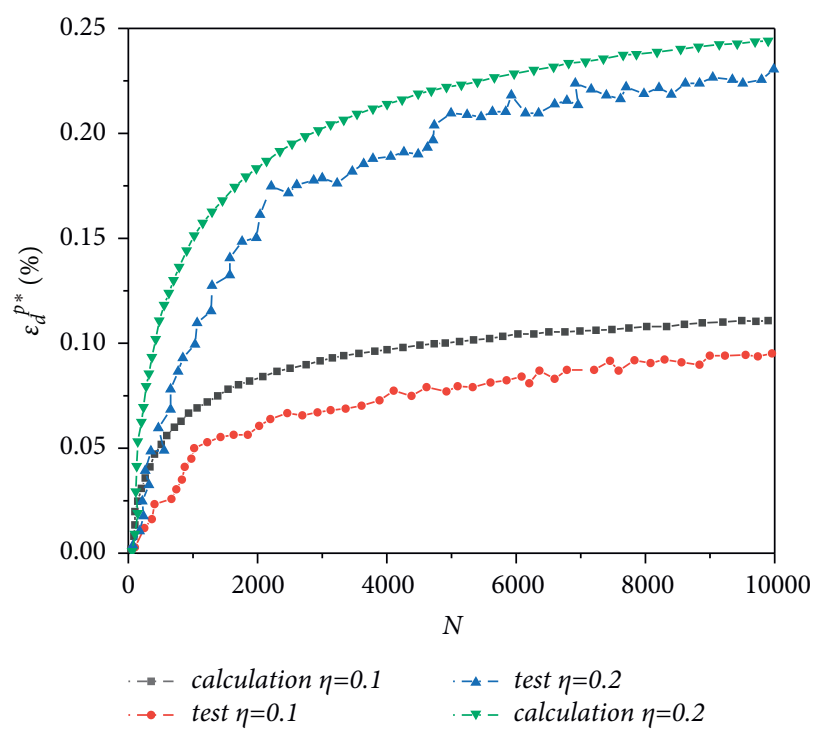

(b)

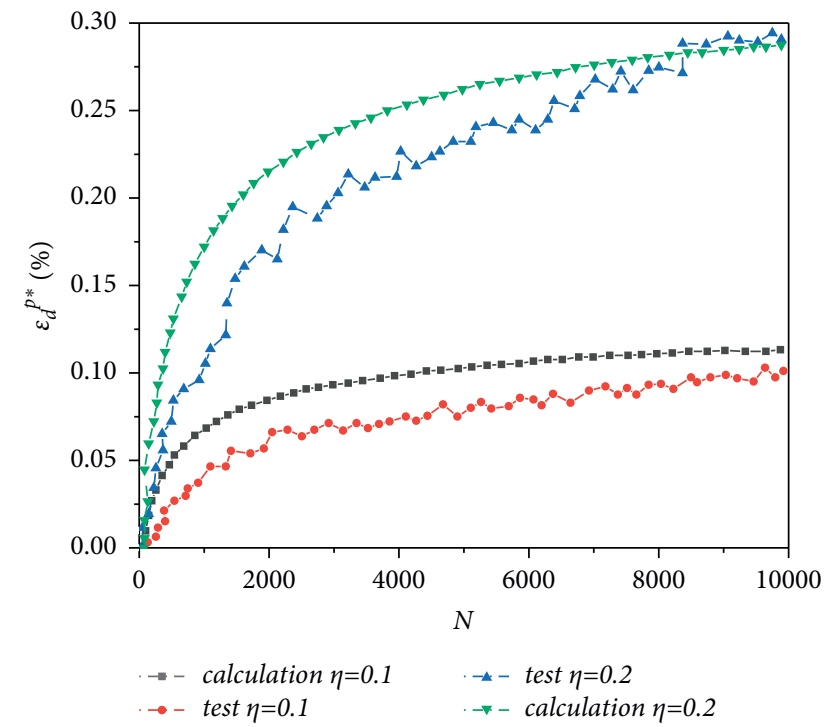

(c)

Figure 9: $N-\varepsilon_{d}^{p *}$ curve at $\sigma_{3}=100 \mathrm{kPa}$. (a) $e_{0}=0.786$, (b) $e_{0}=0.853$, and (c) $e_{0}=0.923$.

results of conventional triaxial experiments by selecting appropriate membership function parameters.

In order to compare and analyze the accuracy of the constitutive model, correlation coefficient $\left(R^{2}\right)$ was obtained by regression analysis [23] as shown in Table 2.

The results show that the model can accurately predict the three-axis of the soil sample when $\alpha=1.85$. For the test soil, the parameters of the calculation model can be taken as $\alpha=1.85$.

As shown in Figures 7 and 8, under different confining pressures, the experimental results, corresponding to the $q-$ $\varepsilon_{d}$ and $\varepsilon_{v}-\varepsilon_{d}$ curves, are in good agreement with the model results. The fuzzy elastoplastic Cambridge model can be used to simulate and analyze conventional triaxial experiments.

3.2. Simple Loading and Unloading Experiment. Under a certain confining pressure, the sample was subjected to a vertical cyclic load to perform a triaxial experiment. The experimental plans are presented in Table 3. The cyclic load was in the form of a sine wave with a frequency of $1 \mathrm{~Hz}$. Because the subgrade soil under traffic load is mostly in a compressed state, loading and unloading take the following form:

$$
q(t)=q_{j}+q_{d} * \sin (2 \pi t)
$$

where $q(t)$ denotes the size of the dynamic load at time $t, q_{j}$ represents the magnitude of the static load, and $q_{d}$ represents the magnitude of the dynamic load.

$e_{0}$ is the initial void ratio, $\eta$ is the stress ratio, and $f$ is the frequency. In accordance with the experimental plan in Table 1, experiments were carried out on the samples under different confining pressures and different initial void ratios, and the relationship curve between the number of cycles and axial plastic cumulative strain was obtained. Using the fuzzy 


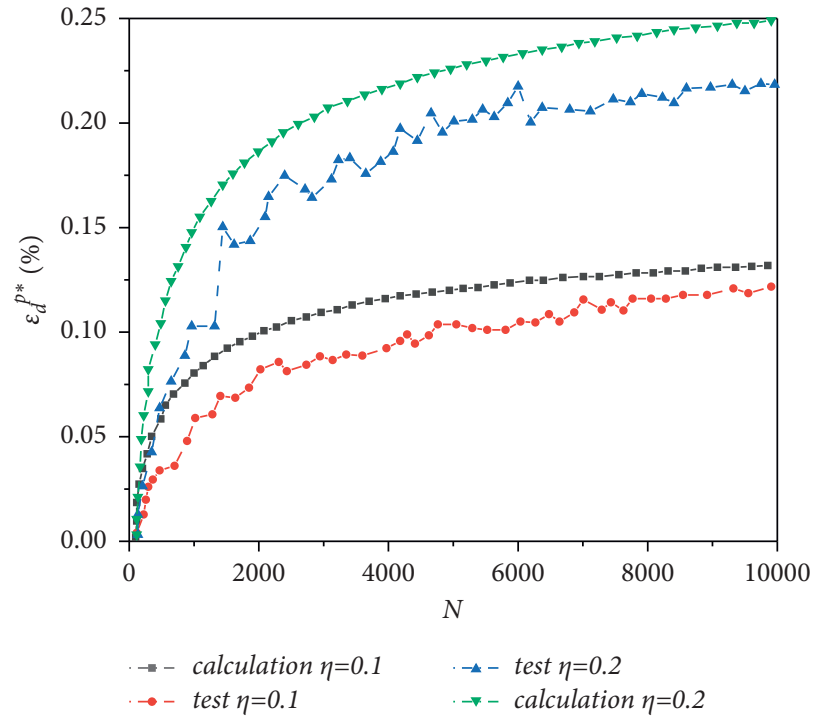

(a)

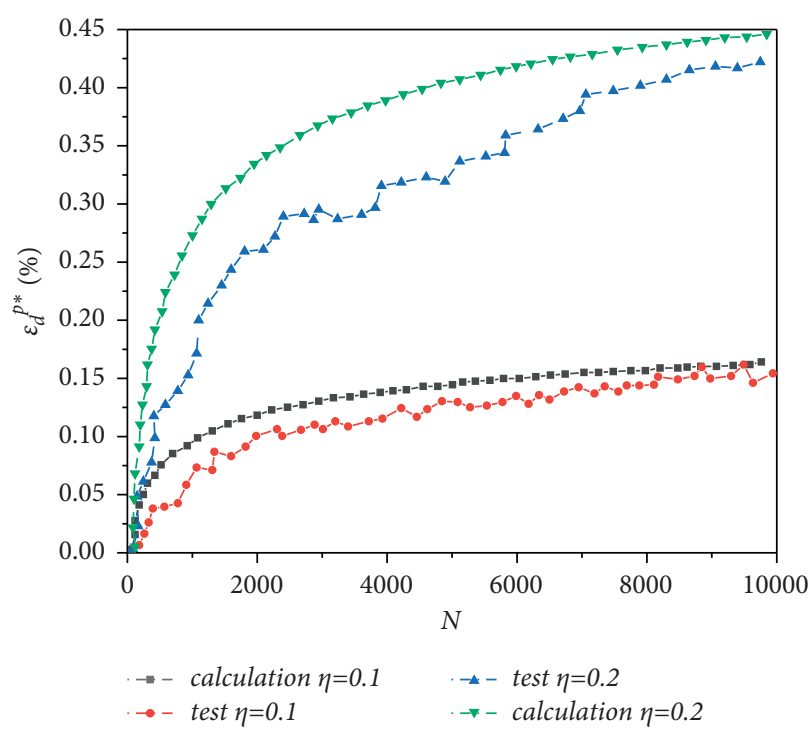

(b)

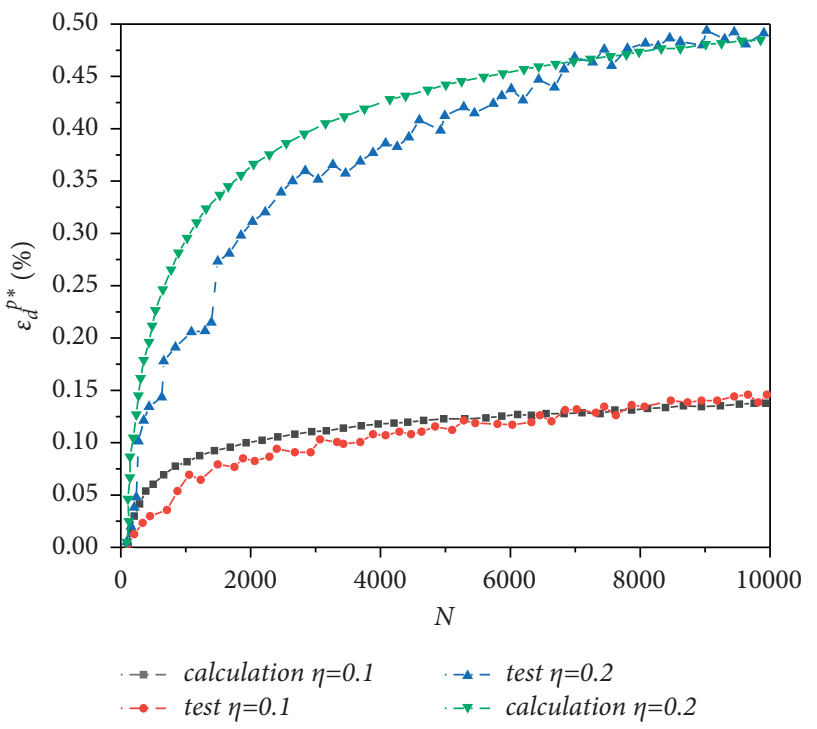

(c)

FIgURE 10: $N-\varepsilon_{d}^{p *}$ curve at $\sigma_{3}=200 \mathrm{kPa}$. (a) $e_{0}=0.786$, (b) $e_{0}=0.853$, and (c) $e_{0}=0.923$.

elastoplastic Cambridge model calculation $(\alpha=1.85)$, the relationship curve between the number of cycles and the axial plastic cumulative strain was obtained. The comparison results between the experimental curve and model calculation curve are shown in Figures 9-12.

Figures 9-12 show that the calculation result for $\alpha=1.85$ is in good agreement with the triaxial result. When the number of cycles is the same, the greater the stress ratio, the greater the plastic strain; the greater the initial void ratio, the greater the plastic strain. As the number of cycles increases, the plastic strain continues to increase.

\subsection{Application of Fuzzy Plastic Model in Roadbed Subgrade}

3.3.1. Boundary Conditions and Loading. The basic roadbed composition is listed in Table 1.

The roadbed is $28 \mathrm{~m}$ wide and $30 \mathrm{~m}$ deep, and according to the concept of modeling in literature, the finite element model of the roadbed is shown in Figure 13.

The boundary conditions of the finite element model of the roadbed are shown in Figure 14. The linear and angular displacements on both sides of the model parallel to the driving direction were restricted. The two sides of the model perpendicular to the direction of travel limit 


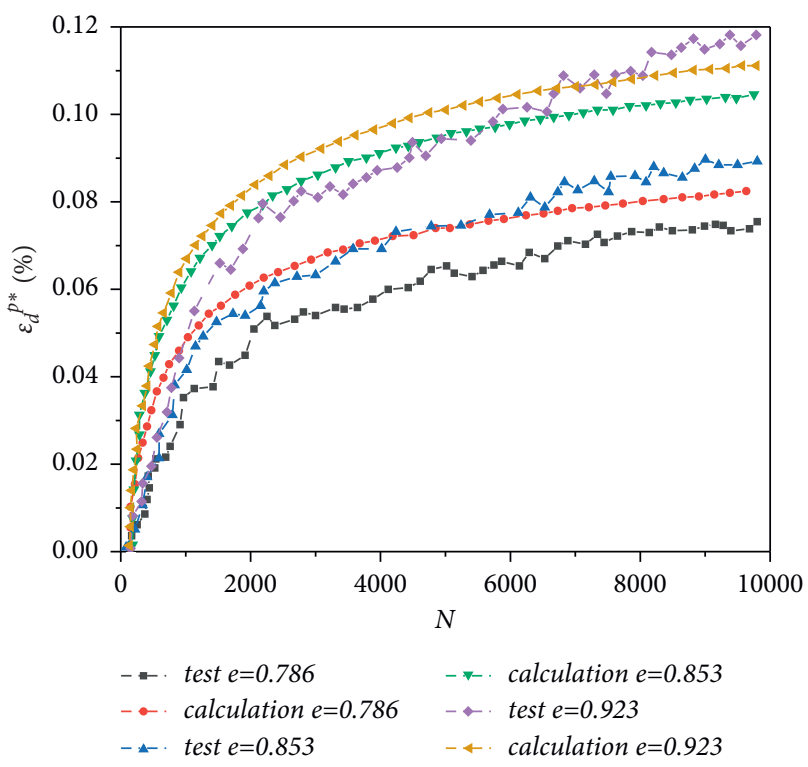

Figure 11: $N-\varepsilon_{d}^{p *}$ curve at $\sigma_{3}=100 \mathrm{kPa}$ and $\eta=0.1$.

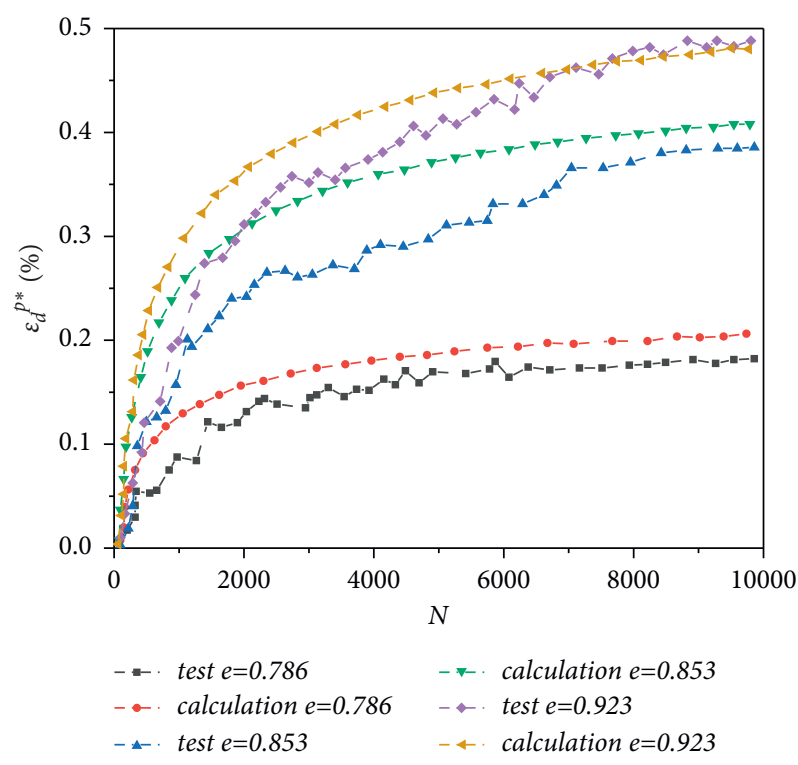

Figure $12: N-\varepsilon_{d}^{p *}$ curve at $\sigma_{3}=200 \mathrm{kPa}$ and $\eta=0.2$.

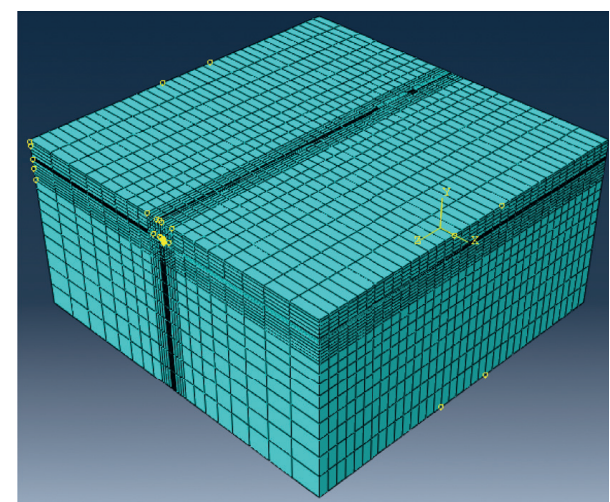

Figure 13: Subgrade FEM model.

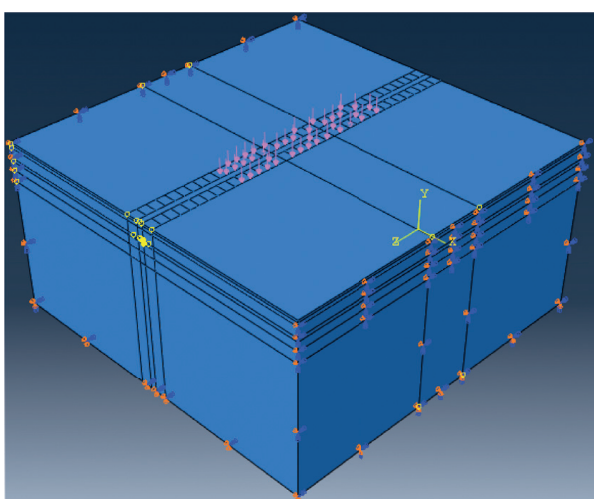

Figure 14: Boundary conditions. 


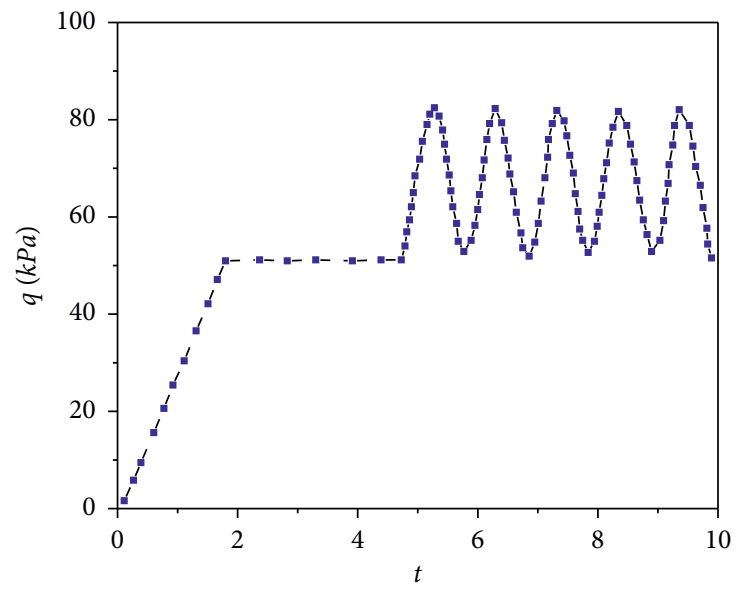

FIGURE 15: Vertical stress time history curve.

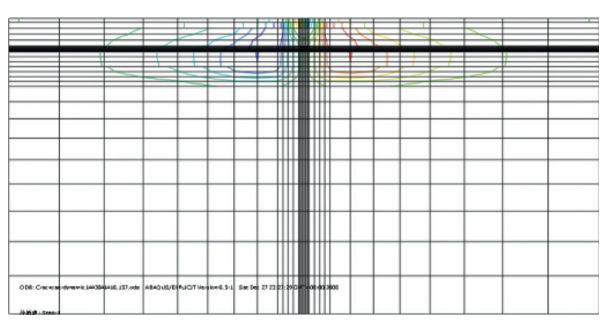

(a)

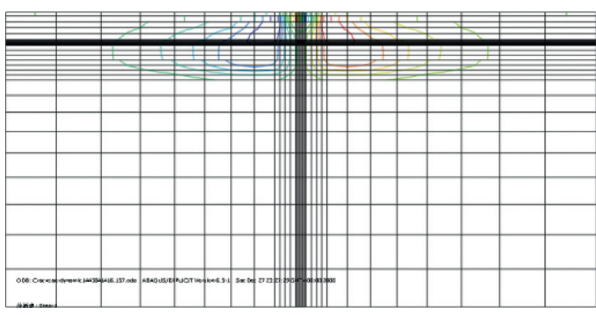

(c)

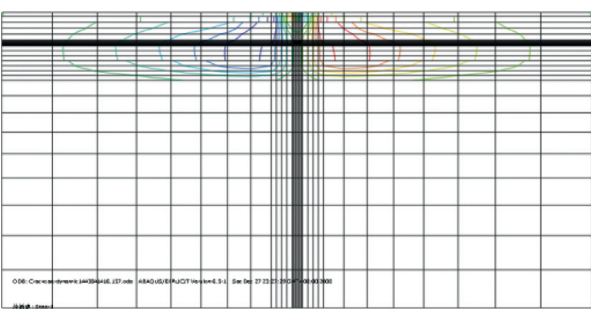

(b)

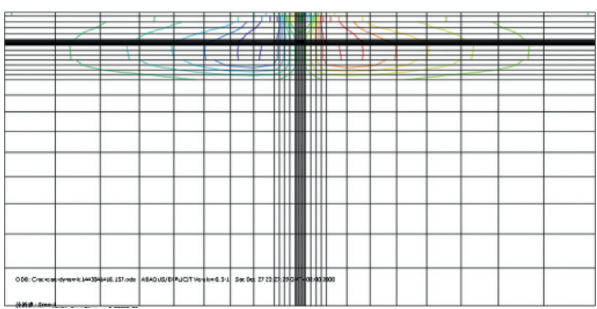

(d)

Figure 16: Periodic shear stress change diagram. (a) $t=1 / 8$, (b) $t=2 / 8$, (c) $t=3 / 8$, and (d) $t=4 / 8$.

TABLE 4: Shear stress at the apex of the roadbed at different times $(\mathrm{kPa})$.

\begin{tabular}{lcc}
\hline Loading moment & $\mu(\sigma)$ & Fuzzy results $(\alpha=1.85)$ \\
\hline $0 / 8$ & 0 & 135 \\
$1 / 8$ & $6 \%$ & 281 \\
$2 / 8$ & $26 \%$ & 585 \\
$3 / 8$ & $77 \%$ & 1163 \\
$4 / 8$ & $100 \%$ & 1320 \\
$5 / 8$ & $74 \%$ & 1143 \\
$6 / 8$ & $24 \%$ & 618 \\
$7 / 8$ & $4 \%$ & 244 \\
$8 / 8$ & 0 & 142 \\
\hline
\end{tabular}

the linear and angular displacements in the $x$ and $y$ directions.

Because most of the subgrade soil is in a compressed state, the loading and unloading law of the subgrade can be expressed as follows:

$$
q(t)=q_{j}+q_{d} * \sin \left(2 \pi t+\frac{3}{2} * \pi\right)
$$

where $q(t)$ represents the magnitude of the dynamic load at time $t$ and $q_{d}$ represents the magnitude of the dynamic load. 


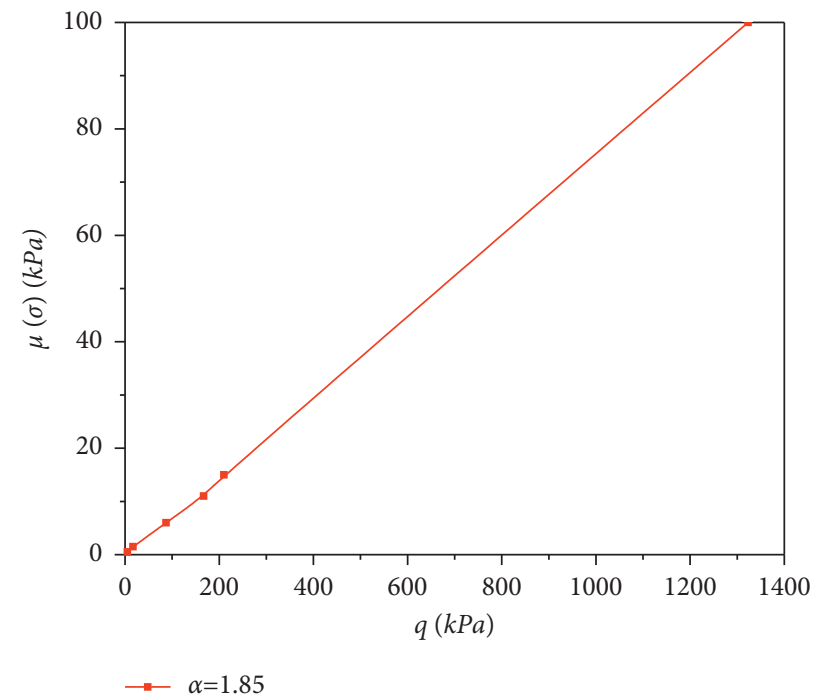

FiguRe 17: Relationship curve between membership degree and shear stress.

TABle 5: Shear stress at different depths and $t=4 / 8(\mathrm{kPa})$.

\begin{tabular}{lcc}
\hline Position $(\mathrm{m})$ & $\mu(\sigma)(\%)$ & Fuzzy results $(\alpha=1.85)$ \\
\hline 0 & 100 & 1320 \\
-5 & 20 & 210 \\
-10 & 11 & 167 \\
-15 & 6 & 87 \\
-20 & 1.5 & 17 \\
-25 & 0.2 & 5 \\
\hline
\end{tabular}

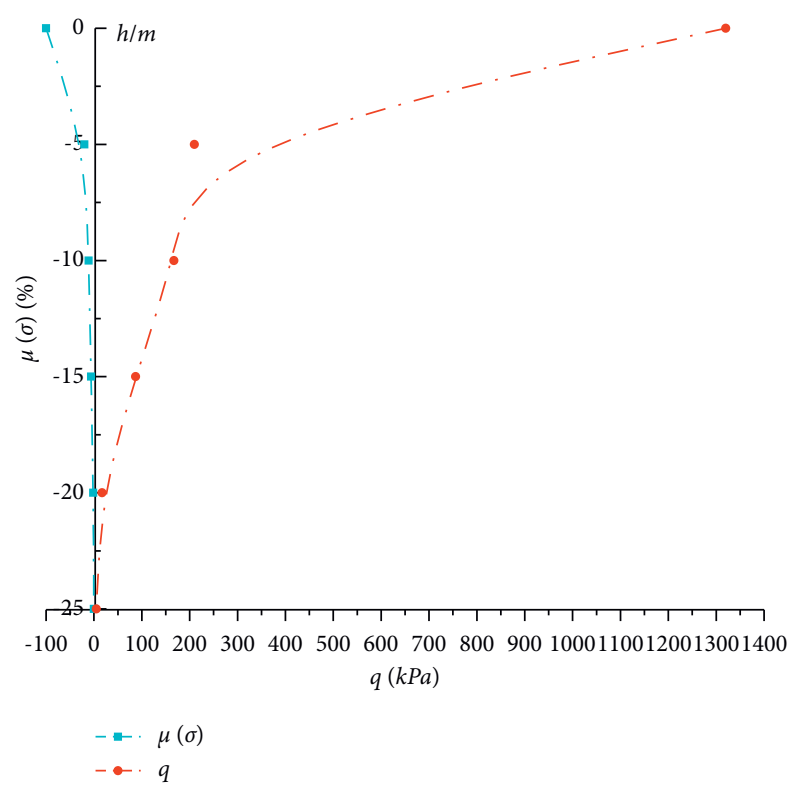

Figure 18: Relationship curve between membership degree and depth. 


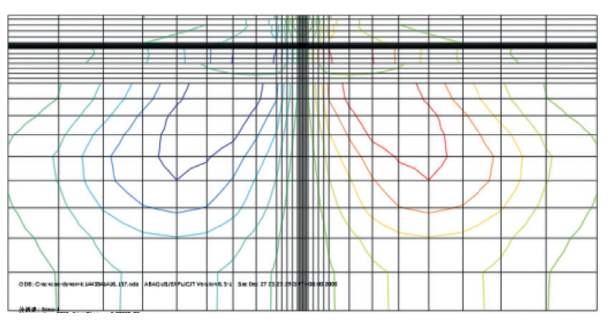

(a)

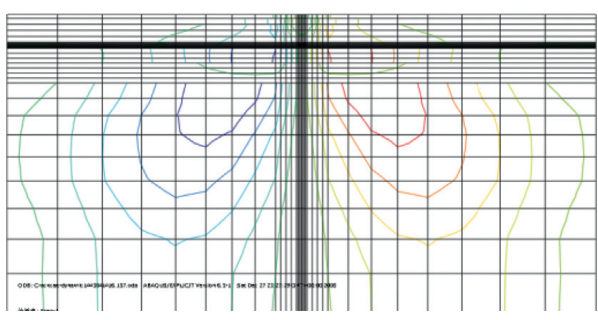

(c)

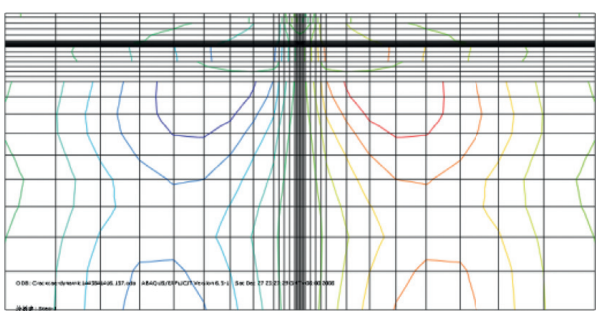

(b)

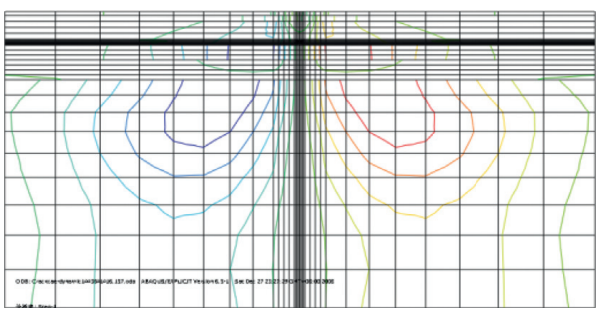

(d)

Figure 19: Vertical strain. (a) $t=1 / 8$, (b) $t=2 / 8$, (c) $t=3 / 8$, and (d) $t=4 / 8$.
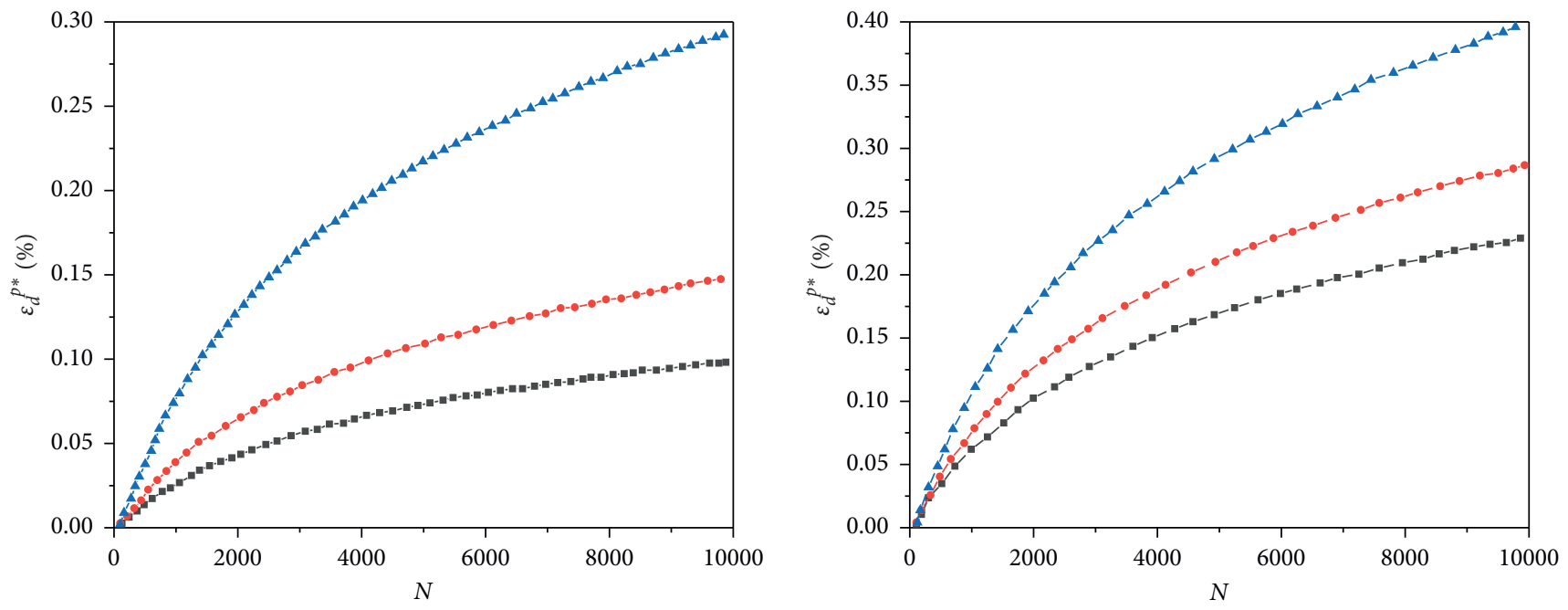

- $f=2$

$\because-f=1.5$

$-x-f=1$

- $f=2$

$\rightarrow-f=1.5$

$-\mathrm{A}-f=1$

(a)

FIgure 20: Continued. 


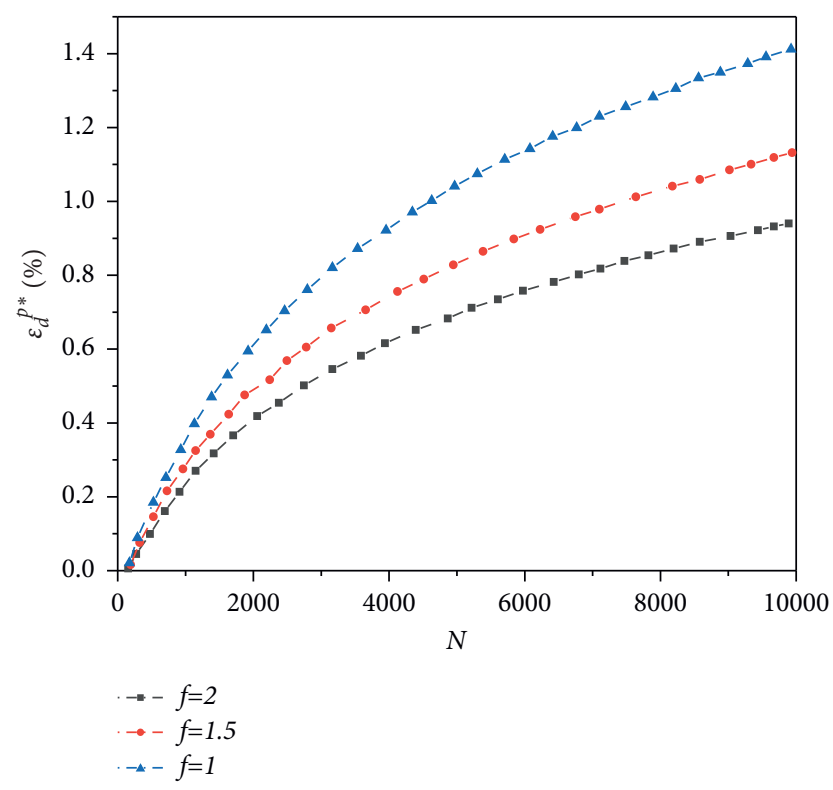

(c)

FIGURE 20: Influence of frequency on the relationship between cumulative plastic strain and number of vibrations. (a) $q_{d}=10 \mathrm{kPa}$, (b) $q_{d}=20 \mathrm{kPa}$, and (c) $q_{d}=30 \mathrm{kPa}$.
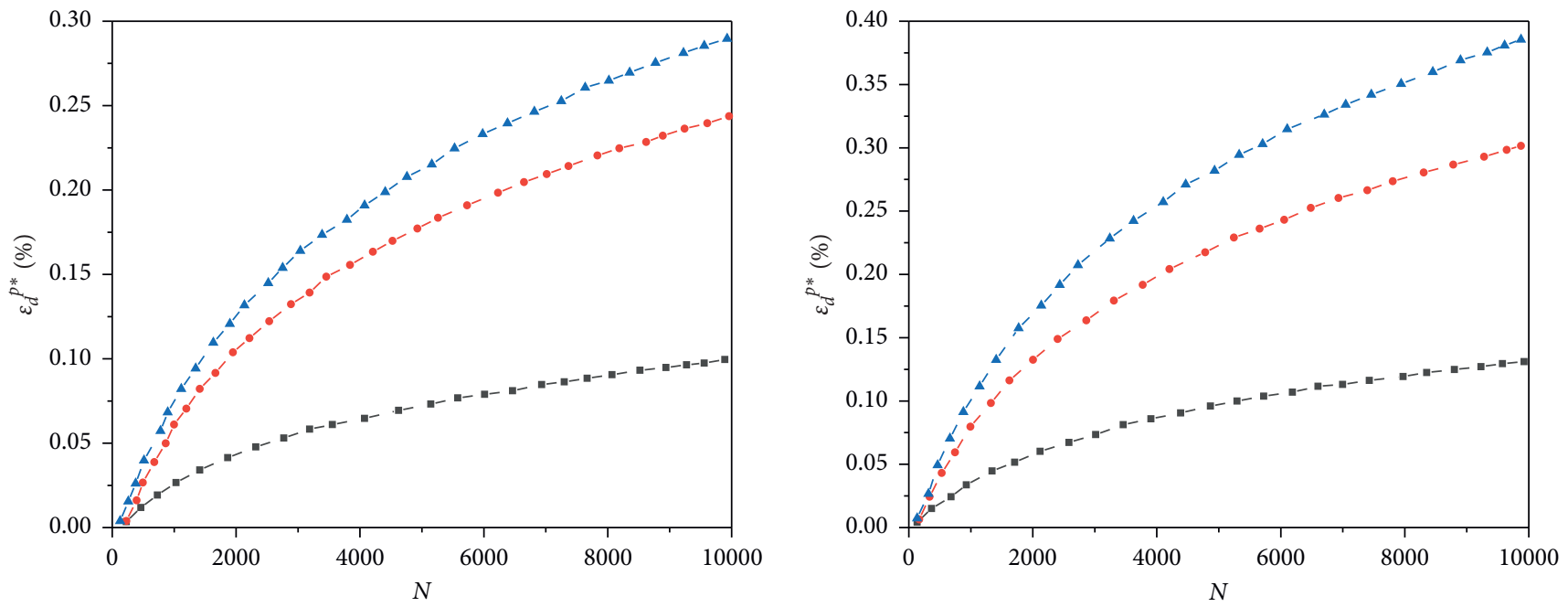

$$
\begin{array}{ll}
\rightarrow- & \eta=0.1 \\
- & \eta=0.2 \\
- & \eta=0.3
\end{array}
$$

$$
\begin{aligned}
& \eta=0.1 \\
& -\eta=0.2 \\
& -\eta=0.3
\end{aligned}
$$

(a)

Figure 21: Continued. 


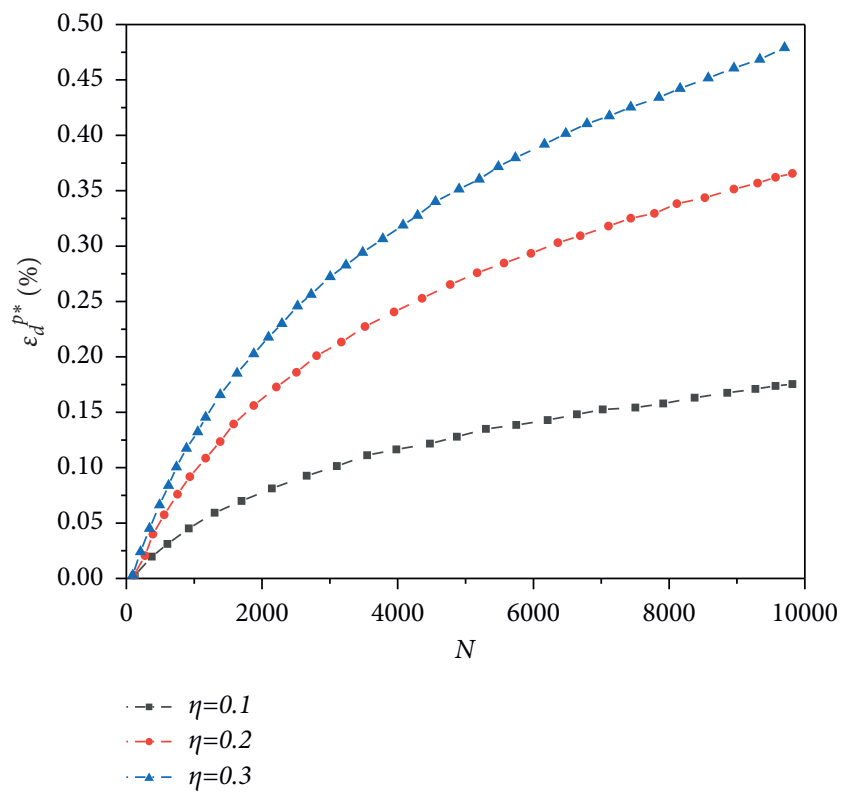

(c)

FIGURE 21: Influence of $\eta$ on the relationship between cumulative plastic strain and number of vibrations. (a) $\sigma_{3}=60 \mathrm{kPa}$, (b) $\sigma_{3}=90 \mathrm{kPa}$, and (c) $\sigma_{3}=120 \mathrm{kPa}$.

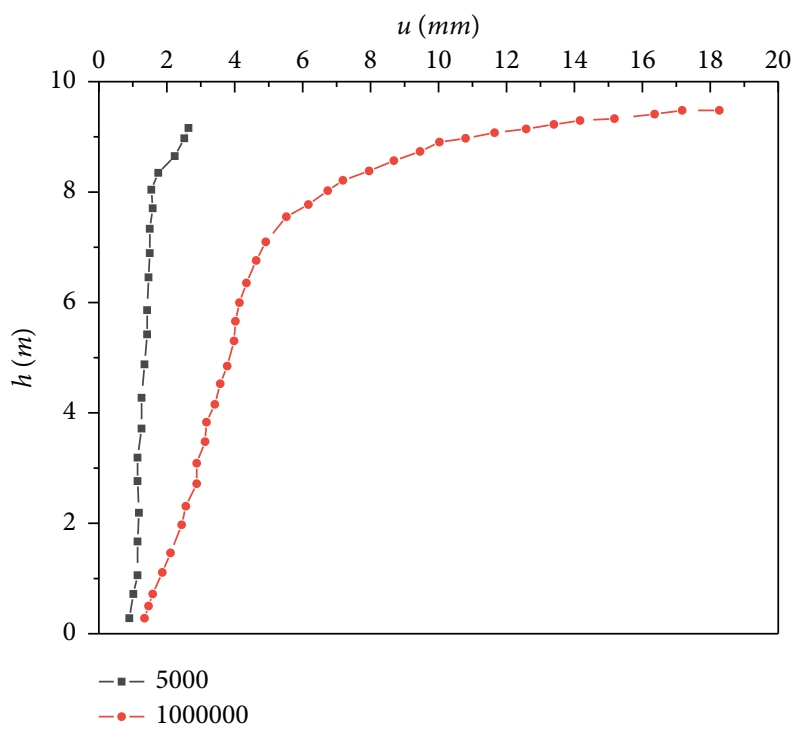

FIGURE 22: Permanent deformation of the subgrade changes along the depth curve.

The vertical stress-time history curve of the subgrade soil loading process is shown in Figure 15.

3.3.2. Result. 3.3.2.1 Stress. The change in the shear stress of the roadbed during a period is shown in Figure 16.

The shear stress changes continuously with time, corresponding to the continuous change in the membership degree with time, which represents the difference between the fuzzy elastoplastic theory and classical plastic theory. The fuzzy elastoplastic constitutive model was used to analyze the vertices of the roadbed directly below the wheels, and the calculation results of the same point over time are summarized in Table 4.

The corresponding relationship between the membership function and shear stress at the apex of the roadbed at different times is shown in Figure 17.

To study the change in stress at different positions at the same time $(t=4 / 8)$, the points taken every $5 \mathrm{~m}$ from the apex of the roadbed along the depth direction constituted the research object, and the results of the vertical stress are summarized in Table 5. 


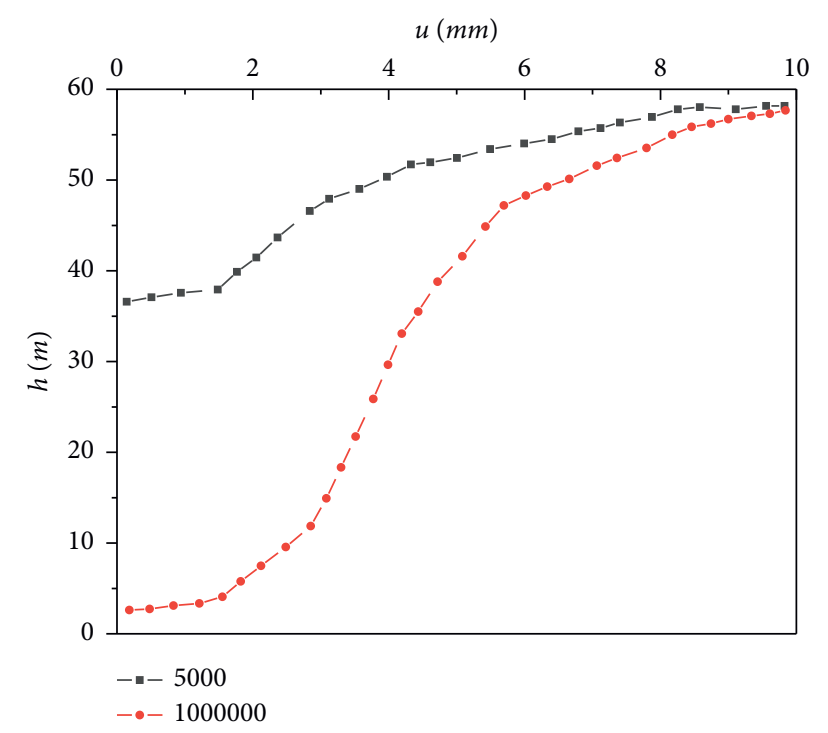

Figure 23: Permanent deformation diagram of the cross section of the subgrade.

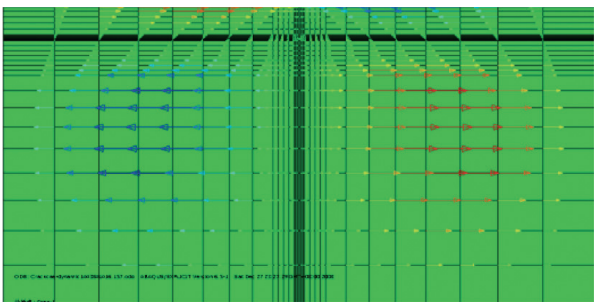

(a)

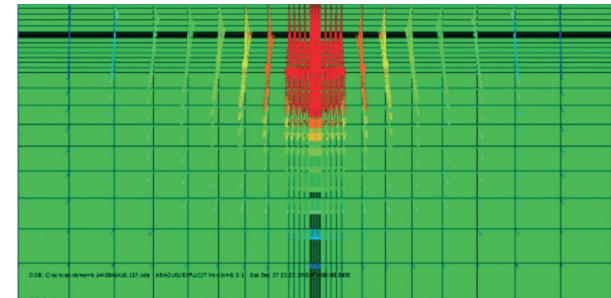

(b)

Figure 24: Development trend of a periodic displacement. (a) Horizontal displacement. (b) Vertical displacement.

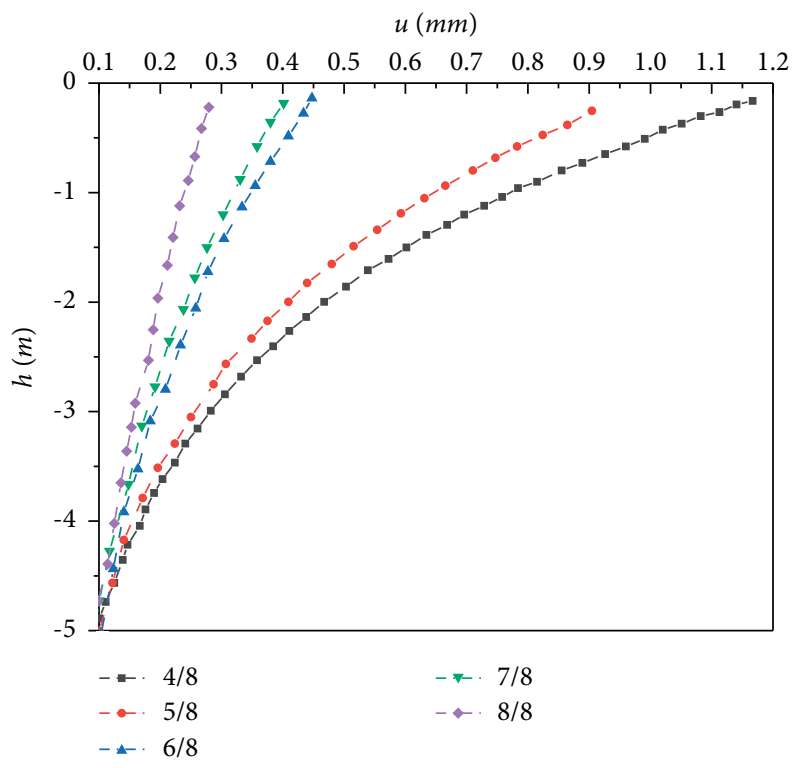

Figure 25: Displacement comparison at different moments. 
The plastic membership degree and shear stress of the soil at different depths under the roadbed are shown in Figure 18.

As presented in Table 4 and Figure 18, the degree of plastic membership and the stress value decrease as the distance from the loading point increases. The results at other times were similar to those at $t=4 / 8$. The stress changes at different positions can be simultaneously represented by the corresponding membership value of the point.

(1) Strain. The vertical strain changes under a cyclic load are shown in Figure 19.

Under different frequencies and dynamic stress ratios, the natural subgrade vertices are studied, and the relationship between the vertical cumulative plastic strain $\varepsilon_{d}^{p}$ of the subgrade and the number of cyclic load vibrations $N$ is obtained, as shown in Figures 20 and 21.

Figures 20 and 21 show that the cumulative plastic strain increases with the number of cycles. When the number of cycles is the same, the greater the dynamic stress ratio, the greater the cumulative plastic strain. Under the same conditions, because the settlement of the roadbed increases with the dynamic stress ratio, traffic loads with large dynamic stress should receive sufficient attention.

(2) Displacement. According to the fuzzy elastoplastic theory, the permanent deformation (settlement) at different depths and the permanent deformation at different widths of the roadbed are calculated, as shown in Figures 22 and 23.

Figures 22 and 23 show that, under the same number of cycles, as the depth increases, the permanent deformation (settlement) of the subgrade continues to decrease, and there is no permanent deformation at $10 \mathrm{~m}$ below the apex of the subgrade. At the same depth, as the number of load cycles increases, the amount of permanent deformation continued to increase, indicating that the plastic strain of the roadbed continues to accumulate.

The development trend of the displacement of the subgrade under the action of a periodic load of $4 / 8$ is shown in Figure 24.

The influence of different dynamic load amplitudes along the depth of a period on the vertical displacement time history is shown in Figure 25.

It can be seen from Figure 25 that the dynamic displacement corresponding to the $4 / 8$ time in each cycle is the largest, and the dynamic displacement corresponding to the $0 / 8$ time is the smallest.

Through the analysis of triaxial tests and subgrade engineering, it is known that fuzzy plasticity theory can well explain the loading and unloading problem of the subgrade under cyclic loading, and fuzzy plasticity theory can obtain similar results with classical plasticity theory.

The core of the fuzzy plasticity theory is to select an appropriate plastic membership function. This study adopts the assignment-type plastic membership function form; however, it cannot accurately reflect the plasticity of the material. In future, we shall use inversion analysis to determine a more appropriate membership function.

\section{Conclusion}

The conclusions of this study can be summarized as follows:

(1) By combining fuzzy mathematics with the modified Cambridge model and using the associated flow law, the fuzzy plastic Cambridge model is obtained. The fuzzy plastic Cambridge model can reflect the plastic strain at any point in the elastic region in the classical initial yield plane.

(2) The fuzzy plastic Cambridge model expresses the cyclic loading and unloading process through the evolution of the plastic membership function, and the magnitude of the material plastic strain is related to the plastic membership function.

(3) Upon selecting an appropriate membership function parameter $\alpha$, the fuzzy elastoplastic constitutive model was observed to be in good agreement with the results of the triaxial test and cyclic loading and unloading tests.

(4) The fuzzy elastic-plastic constitutive model was used to calculate the stress, strain, and displacement of the subgrade under cyclic loading.

\section{Data Availability}

The data used to support the findings of this study are included within the article.

\section{Conflicts of Interest}

The authors declare that they have no conflicts of interest.

\section{Acknowledgments}

This research was funded by Doctor Startup Fund Program by Department of Science and Technology of Liaoning Province (Grant number 20180540101).

\section{References}

[1] S. R. Bodner and Y. Partom, "A large deformation elasticviscoplastic analysis of a thick-walled spherical shell," Journal of Applied Mechanics, vol. 39, no. 3, pp. 751-757, 1972.

[2] K. C. Valanis, "Theory of viscoplasticity without a yield surface. Part I: general theory. Part II: application to mechanical behavior of metals," Archives of Mechanics, vol. 23, pp. 517-551, 1971.

[3] D. A. Sangrey, D. J. Henkel, and M. I. Esrig, "The effective stress response of a saturated clay soil to repeated loading," Canadian Geotechnical Journal, vol. 6, no. 3, pp. 241-252, 1969.

[4] J. W. France and D. A. Sangrey, "Effects of drainage in repeated loading of clays," Journal of the Geotechnical Engineering Division, vol. 103, no. 7, pp. 769-785, 1977.

[5] H. Fuijiwara, T. Yamanouchr, K. Yasuhara, and S. Ue, "Consolidation of alluvial clay under repeated loading," Soils and Foundations, vol. 25, no. 3, pp. 19-30, 1985.

[6] H. Fuijiwara, S. Ue, and K. Yasuhara, "Secondary compression of clay under repeated loading," Soils and Foundations, vol. 27, no. 2, pp. 21-30, 1987. 
[7] H. Xiaorong, X. Cai, P. Qu, C. Xiaofeng, and Q. Peng, "Tripleshear elastoplastic constitutive models for normally consolidated unsaturated soils based on the coordinate translation method," Applied Mathematics and Mechanics, vol. 42, no. 8, pp. 813-831, 2021.

[8] L. Zhang and X. Wang, "Study on nonlinear damage creep model for Rocks under cyclic loading and unloading," $A d$ vances in Materials Science and Engineering, vol. 2021, Article ID 5512972, 10 pages, 2021.

[9] L. Wu, K. Zhou, F. Gao, Z. Gu, and C. Yang, "Research on the mechanical characteristics of cyclic loading and unloading of rock based on infrared thermal image analysis," Mathematical Problems in Engineering, vol. 202116 pages, 2021.

[10] X. Li, K. Peng, J. Peng, and D. Hou, "Effect of thermal damage on mechanical behavior of a fine-grained sandstone," Arabian Journal of Geosciences, vol. 14, no. 13, p. 1212, 2021.

[11] D. Ma, S. Kong, Q. Zhang, Z. Wang, and Z. Zhou, "Effect of wetting-drying cycle on hydraulic and mechanical properties of cemented paste backfill of the recycled solid wastes," Chemosphere, vol. 282, Article ID 131163, 2021.

[12] D. Ma, H. Duan, J. Liu, X. Li, and Z. Zhou, "The role of gangue on the mitigation of mining-induced hazards and environmental pollution: an experimental investigation," The Science of the Total Environment, vol. 664, pp. 436-448, 2019.

[13] L. A. Zadeh, "Fuzzy sets," Information and Control, vol. 8, no. 1, pp. 338-353, 1965.

[14] M. Klisinski, "Plasticity theory based on fuzzy sets," Journal of Engineering Mechanics, ASCE, vol. 114, no. 4, pp. 563-582, 1988.

[15] M. Fu, B. Xu, and Z. Xiong, "Problem of fuzzy elasto-viscoplasticity and uniqueness and existence of the solution," Journal of Jiangsu Polytechnic University, vol. 14, no. 1, pp. 1-11, 1992.

[16] M. Fu, B. Xu, and Z. Xiong, "Analysis of fuzzy elasto-viscoplasticity for spherical shell," Engineering Mechanics, vol. 11, no. 2, pp. 1-7, 1994.

[17] X. Wang and M. Fu, "Fuzzy elasto-visco-plasticity analysis of finite deformation based on the L-D plastic flow rule," Applied Mathematics and Mechanics, vol. 36, no. 2, pp. 128-139, 2015.

[18] X. Wang, M. Fu, and X. Hu, "Bounding surface model based on membership function under cyclic loading," Journal of Harbin Engineering University, vol. 36, no. 12, pp. 1560-1564, 2015.

[19] X. Wang and M. Fu, "Research for constitutive model of fuzzy elastic-plasticity by membership function," Journal of Vibration and Shock, vol. 34, no. 23, pp. 115-120, 2015.

[20] Y. Yin, Nonlinear Finite Element Basis, Peking University Press, Beijing, China, 2007.

[21] G. Xu, L. Yao, Z. Gao, and Z. Li, "Large-scale shaking table model test study on dynamic characteristics and dynamic responses of slope," Chinese Journal of Rock Mechanics and Engineering, vol. 27, no. 3, pp. 624-632, 2008.

[22] D. Luo, Y. Yao, and W. Huo, Soil Constitutive Models, China Communications Press, Beijing, China, 2010.

[23] J. Zhang, J. Peng, A. Zhang, and J. Li, "Prediction of permanent deformation for subgrade soils under traffic loading in Southern China," International Journal of Pavement Engineering, vol. 21, pp. 1-10, 2020. 